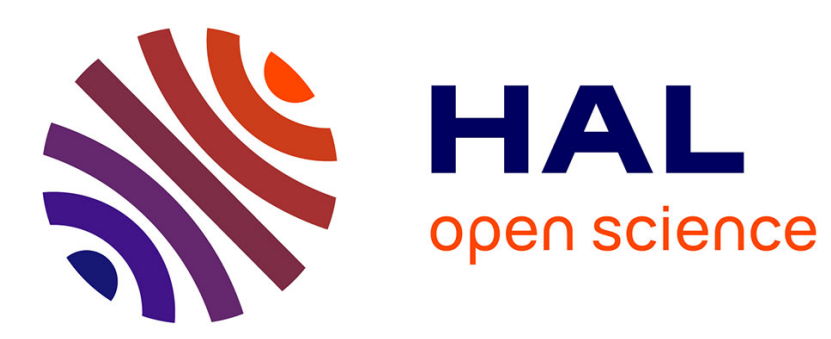

\title{
Gliding for a free lunch: biomechanics of foraging flight in common swifts (Apus apus)
}

Tyson L. Hedrick, Cécile Pichot, Emmanuel de Margerie

\section{To cite this version:}

Tyson L. Hedrick, Cécile Pichot, Emmanuel de Margerie. Gliding for a free lunch: biomechanics of foraging flight in common swifts (Apus apus). Journal of Experimental Biology, 2018, 221 (22), pp.jeb186270. 10.1242/jeb.186270 . hal-01928514

HAL Id: hal-01928514

\section{https://hal-univ-rennes1.archives-ouvertes.fr/hal-01928514}

Submitted on 21 Nov 2018

HAL is a multi-disciplinary open access archive for the deposit and dissemination of scientific research documents, whether they are published or not. The documents may come from teaching and research institutions in France or abroad, or from public or private research centers.
L'archive ouverte pluridisciplinaire HAL, est destinée au dépôt et à la diffusion de documents scientifiques de niveau recherche, publiés ou non, émanant des établissements d'enseignement et de recherche français ou étrangers, des laboratoires publics ou privés. 


\title{
Gliding for a free lunch: biomechanics of foraging flight in common swifts (Apus apus)
}

\author{
Tyson L. Hedrick ${ }^{1, *}$, Cécile Pichot ${ }^{2}$ and Emmanuel de Margerie ${ }^{2, *}$
}

\begin{abstract}
Although the biomechanics of animal flight have been well studied in laboratory apparatus such as wind tunnels for many years, the applicability of these data to natural flight behaviour has been examined in few instances and mostly in the context of long-distance migration. Here, we used rotational stereo-videography to record the free-flight trajectories of foraging common swifts. We found that, despite their exquisite manoeuvring capabilities, the swifts only rarely performed high-acceleration turns. More surprisingly, we also found that despite feeding on tiny insects probably moving with ambient flow, the birds adjust their air speed to optimize cost of transport over distance. Finally, swifts spent only $25 \%$ of their time flapping; the majority of their time $(71 \%)$ was spent in extended wing gliding, during which the average power expended for changes in speed or elevation was $0.84 \mathrm{~W} \mathrm{~kg}^{-1}$ and not significantly different from 0 . Thus, gliding swifts extracted sufficient environmental energy to pay the cost of flight during foraging.
\end{abstract}

KEY WORDS: Glide polar, Kinematics, Rotational stereo videography, Soaring, Thermal, Wind

\section{INTRODUCTION}

Common swifts (Apus apus) are coursing aerial insectivores known to spend the majority of their life on the wing, even sleeping while in flight and staying in the air for up to 10 months at a time (Hedenström et al., 2016). However, breeding and rearing their young tie the birds to a particular location and require local foraging along with frequent returns to the nest. This provides an opportunity for quantifying free-flight foraging biomechanics with high spatial and temporal resolution for comparison with data collected from wind tunnel experiments (e.g. Henningsson and Hedenström, 2011; Henningsson et al., 2011a; Lentink et al., 2007) and linking these underlying biomechanical performance measures to natural flight behaviour.

Here, we quantified swift flight trajectories by rotational stereo videography (RSV), which uses a camera and telephoto lens with a set of mirrors to combine views from two vantage points into one image, all mounted on an instrumented pivot to track individual birds during flight (de Margerie et al., 2015). Application of this and other videographic methods enables measurement of field flight biomechanics with high spatial (centimetre-metre scale) and

\footnotetext{
${ }^{1}$ University of North Carolina at Chapel Hill, Chapel Hill, NC 27599, USA. ${ }^{2}$ CNRS, Université de Rennes, Normandie Univ., EthoS (Ethologie animale et humaine)UMR 6552, F-35000 Rennes, France.

*Authors for correspondence (thedrick@bio.unc.edu; emmanuel.demargerie@univ-rennes1.fr)

D T.L.H., 0000-0002-6573-9602; C.P., 0000-0003-0510-1946; E.d.M., 0000-00025380-3355
}

Received 7 June 2018; Accepted 10 September 2018 temporal $(5-100 \mathrm{~Hz})$ resolution, even for species where use of an on-board satellite-based positioning package is currently infeasible because of weight or other restrictions. Application of video measurement methods has already revealed flight speeds well beyond those achieved in wind tunnels by quantifying mating or display behaviour in common swifts (Henningsson et al., 2010) and hummingbirds (Clark, 2009), along with high-speed turns and pursuits in cliff swallows (Shelton et al., 2014). Field trajectory recordings also revealed energy extraction from the ground to air wind speed gradient by foraging barn swallows (Warrick et al., 2016). In the recordings of the present study, the common swifts were also engaged in foraging, permitting comparison with the foraging flight dynamics of two evolutionarily distinct coursing aerial insectivores (swallows and swifts) as well as comparison of natural and wind tunnel flight in swifts.

The prior wind tunnel studies on gliding (Henningsson and Hedenström, 2011) and flapping flight (Henningsson et al., 2011a, b) in swifts and models of the effect of wind speed and direction on optimal bird airspeed (Pennycuick, 1978) provide a series of testable hypotheses on how flight biomechanics relate to flight behaviour. First, the observed flight performance in gliding and flapping is expected to conform to the glide polar and flight power curves measured in wind tunnel experiments, with swifts losing potential energy during gliding and adding kinetic or potential energy while flapping. Wind tunnel experiments with live birds (Henningsson and Hedenström, 2011) and preserved wings (Lentink et al., 2007) measured maximum lift to drag ratios in gliding flight of 12.5 and 10.0, respectively, at flight speeds of 9.5 and $9.0 \mathrm{~m} \mathrm{~s}^{-1}$. This is also close to the preferred flight speed of a swift in flapping flight in a wind tunnel (Henningsson et al., 2011b) and thus the modal airspeed of free-flying swifts is hypothesized to be near $9 \mathrm{~m} \mathrm{~s}^{-1}$. Extreme flight speeds reached by swifts during group social bonding-related events (Henningsson et al., 2010) are not expected to appear in foraging flight behaviour as these are likely to be costly and of little use in capturing small, slow-moving prey. Second, theory predicts (Pennycuick, 1978), and studies of migrating or commuting birds have confirmed (e.g. Hedenström et al., 2002; Kogure et al., 2016; Wakeling and Hodgson, 1992), that birds should adjust their airspeed when flying upwind or downwind for energetically optimal cost of transport over ground. However, swifts forage mostly on small aerial prey: mainly aphids, complemented with ant, fly, beetle or spider species of less than $5 \mathrm{~mm}$ length, depending on location and season (Lack and Owen, 1955; Gory, 2008). Because these species belong to aeroplankton and move with the wind (Geerts and Miao, 2005; Wainwright et al., 2017), we hypothesize that swifts optimize transport in the air (rather than ground) reference frame and thus do not adjust airspeed with wind speed. Third, foraging barn swallows appear to extract energy from vertical wind shear accessible in their near-ground foraging activities. Common swifts typically forage higher in the atmosphere where vertical wind shear should be less common but 


\section{List of symbols and abbreviations \\ a acceleration vector in the air reference frame, adjusted to account for $\rho$ \\ wind speed vector \\ magnitude of centripetal acceleration \\ magnitude of gravitational acceleration \\ body mass \\ mass-specific rate of change in kinetic and potential energy \\ mass-specific rate of change in kinetic energy \\ mass-specific rate of change in potential energy \\ radius of curvature \\ rotational stereo videography \\ wing area \\ ground speed \\ velocity vector in the ground reference frame \\ velocity vector in the air reference frame, adjusted to account for $\rho$ \\ airspeed, adjusted to account for $\rho$ \\ ground reference Cartesian position in the $X$ direction, computed from smoothed inputs \\ ground reference Cartesian position in the $Y$ direction, computed from smoothed inputs \\ ground reference Cartesian position in the $Z$ direction, \\ computed from smoothed inputs \\ azimuthal angle measurement from RSV \\ air density \\ air density at standard temperature and pressure \\ radial distance measurement from RSV \\ elevation angle measurement from RSV \\ dot-over character, indicating first derivative with respect to time \\ double dot-over character, indicating second derivative with respect to time \\ Subscript e equivalent airspeed or a quantity based on equivalent airspeed Subscript s smoothed}

we hypothesize that they take advantage of other environmental energy sources such as thermals to reduce the cost of foraging. Lastly, barn swallow flight manoeuvres during foraging are typically low energy and the birds appear to depend on a fast approach to unsuspecting prey rather than a sharp turn to catch evasive prey (Warrick et al., 2016). We expect that common swifts operate similarly because wing loading and thus flight speed tends to increase with body size. Turning manoeuvres during barn swallow foraging were facilitated by flapping rather than depending solely on gliding flight performance and we hypothesize the same will be true here.

\section{MATERIALS AND METHODS}

\section{Recording site, times and methods}

Common swifts, Apus apus (Linnaeus 1758), were recorded at the Beaulieu University Campus in Rennes, France during six sessions between 17 June and 9 July 2015. Recordings were conducted between 09:00 $\mathrm{h}$ and 13:00 $\mathrm{h}$ from the second-floor balcony of a campus building using RSV (Fig. 1) with a DMC-GH4 camera (Panasonic, Osaka, Japan) and $200 \mathrm{~mm} \mathrm{f} / 4$ Ai lens (Nikon Inc., Tokyo, Japan). Four first-surface mirrors (FSM, Toledo, OH, USA) were used to project stereo images on the single camera sensor (see de Margerie et al., 2015, for details). Bird positions were sampled at $6 \mathrm{~Hz}$. Longer recordings $(\geq 50 \mathrm{~s})$ in this dataset were previously examined from a behavioural ecology perspective to determine the spatial search strategies used by these birds; additional details on the recording methods and site are provided in that manuscript (de Margerie et al., 2018). For the present work, shorter recordings
(30-50 s) were added to the dataset, along with categorical information on flight behaviour for all recordings (flapping, gliding, etc.), based on detailed observation of RSV images at $30 \mathrm{~Hz}$, downsampled to match the $6 \mathrm{~Hz}$ position recording frequency. RSV recordings contained an average of $2.9 \%$ (14.4 frames, $2.4 \mathrm{~s}$ ) of missing positions, caused by difficulties in keeping the bird within the RSV field of view. These missing positions were interpolated during smoothing because the smoothing operations require continuous data, but were later removed from the biomechanical analysis.

\section{Smoothing}

This kinematics-focused examination of the swift foraging dataset used a different smoothing method from the previous foraging ecology analysis (de Margerie et al., 2018), with more attention given to correctly smoothing the velocities and accelerations. The RSV method natively produces position measurements in a spherical coordinate system $\Theta, \Phi, P$ (i.e. azimuthal angle, elevation angle and radius), with a measurement uncertainty for $\mathrm{P}$ that increases proportional to $\mathrm{P}^{2}$ and is a fixed property of the device for $\Theta$ and $\Phi$ (de Margerie et al., 2015). The cumulative outcome of these uncertainties in 3D Cartesian space is a random position uncertainty attaining $0.2,0.8$ and $1.8 \mathrm{~m}$ at 100,200 and $300 \mathrm{~m}$, respectively. Because $\mathrm{P}$ varies widely within each recording, we used a smoothing spline with per-point error tolerance for $\Theta, \Phi$ and $\mathrm{P}$ determined by these theoretical considerations to smooth the raw coordinate data. Once the smoothed spherical coordinate quantities $\Theta_{\mathrm{s}}, \Phi_{\mathrm{s}}, \mathrm{P}_{\mathrm{s}}$ were determined, they were converted to Cartesian coordinates $X, Y, Z$ for further analysis without application of any additional smoothing. Smoothed first and second derivatives of position with respect to time (i.e. $\dot{X}, \dot{Y}, \dot{Z}$ and $\ddot{X}, \ddot{Y}, \ddot{Z}$ ) were computed by differentiating the smoothing spline functions for $\Theta, \Phi$ and $\mathrm{P}$ to produce $\dot{\Theta}_{\mathrm{s}}, \ddot{\Theta}_{\mathrm{s}}$, etc. We computed $\dot{X}, \dot{Y}, \dot{Z}$ and $\ddot{X}, \ddot{Y}, \ddot{Z}$ from these values, using the derivatives of the underlying spherical to Cartesian conversion equations, e.g.:

$$
\begin{gathered}
Z=\mathrm{P}_{\mathrm{s}} \sin \left(\Phi_{\mathrm{s}}\right), \\
\dot{Z}=\sin \left(\Phi_{\mathrm{s}}\right) \dot{\mathrm{P}}_{\mathrm{s}}+\cos \left(\Phi_{\mathrm{s}}\right) \mathrm{P}_{\mathrm{s}} \dot{\Phi}_{\mathrm{s}}, \\
\ddot{Z}=\sin \left(\Phi_{\mathrm{s}}\right) \ddot{P}_{\mathrm{s}}+2 \cos \left(\Phi_{\mathrm{s}}\right) \dot{\Phi}_{\mathrm{s}} \dot{\mathrm{P}}_{\mathrm{s}}-\sin \left(\Phi_{\mathrm{s}}\right) \mathrm{P}_{\mathrm{s}} \dot{\Phi}_{\mathrm{s}}^{2} \\
+\cos \left(\Phi_{\mathrm{s}}\right) \mathrm{P}_{\mathrm{s}} \ddot{\Phi}_{\mathrm{s}} .
\end{gathered}
$$

No further smoothing was applied to the resulting Cartesian velocity and acceleration values. Because of the dependence of measurement uncertainty on $\mathrm{P}^{2}$, i.e. the square of distance from the RSV device, at some distance biologically important movements will become undetectable. In this case, we observed that the average magnitude of accelerations began to drop at $300 \mathrm{~m}$; data beyond this point would still be suitable for analyses that depend on position or velocity, but not our calculations (see below) for kinematic power. Thus, we removed all flight segments greater than $300 \mathrm{~m}$ distance from the RSV device from further analysis. Moreover, we trimmed the first and last 15 positions $(2.5 \mathrm{~s})$ of tracks in order to remove any edge effect on smoothing. Smoothed tracks of less than $25 \mathrm{~s}$ non-interpolated duration were removed from the dataset.

\section{Wind measurement and environmental conditions}

Local wind speed and direction in the horizontal plane were recorded by releasing and tracking a helium-filled balloon once per hour. We combined this wind vector with the ground reference frame data from the RSV device to put the kinematics in an air-fixed 


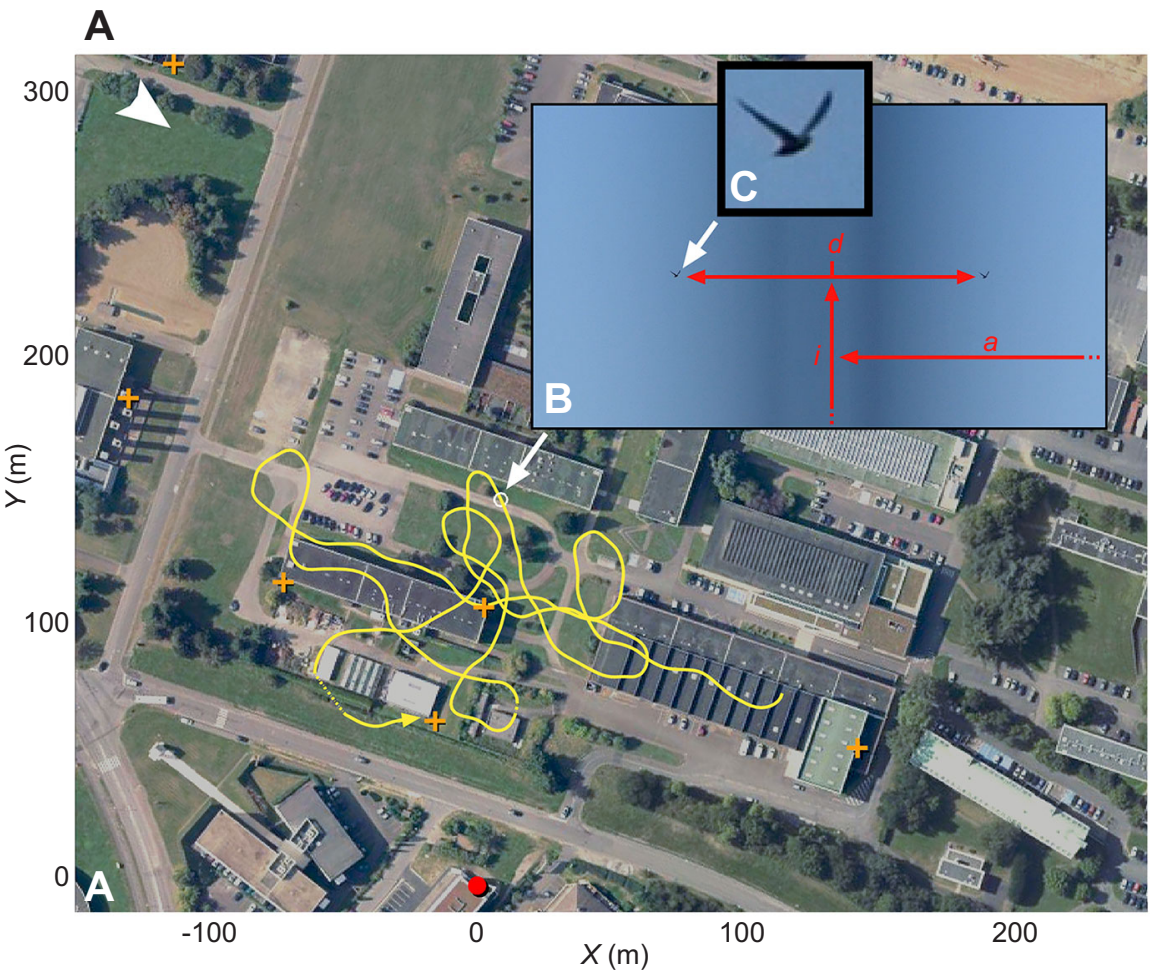

Fig. 1. Data collection methods and location. (A) A $2 \mathrm{D}$ aerial view of the recording location. The red dot at $[0,0]$ coordinates indicates the RSV device location, set up on a building balcony. Orange crosses indicate fixed points used for distance measurement calibration. The yellow line shows an example individual common swift track, composed of $6053 \mathrm{D}$ positions (flight duration $100.4 \mathrm{~s}$, length $1002.5 \mathrm{~m}$; smoothed track is shown). Dotted lines indicate two missing track segments (1 and 10 positions, respectively). (B) Rotational stereo videography (RSV) video frame $(1920 \times 1080$ pixels, $416 \mathrm{~mm}$ equivalent lens), for a single 3D position. The lateral distance between the stereo images of the bird is used to compute distance $(d)$ from camera to bird (through a calibration curve, see de Margerie et al., 2015). The vertical and horizontal position of the bird in the frame, added to an angular record of the camera aiming angle, allowed us to compute the bird's inclination (i) and azimuth (a) relative to the local frame of reference (i.e. RSV tripod). (C) A magnified view of the bird image, from which flight behaviour (e.g. flapping versus gliding) can be assessed. For an animated view of bird flight data, see Movie 1. Source for aerial view: Geoportail, IGN

reference frame. Temperature, barometric pressure and humidity data were gathered from the meteorological station at RennesSaint-Jacques airport, $10 \mathrm{~km}$ southwest of the recording location. Air density was $1.193 \pm 0.024$ (mean \pm s.d.). For flight power requirements and determination of the glide polar, the air reference frame velocity and acceleration vectors were adjusted to equivalent airspeed by multiplying by the square root of the ratio of observed to standard air density for velocity (and the ratio for accelerations). In all other cases, we report values based on observed airspeed because we do not know whether the birds prioritize observed performance (i.e. indicated airspeed, observed centripetal acceleration, etc.) or flight effort (i.e. equivalent airspeed). Furthermore, the small difference between observed and standard air density makes the differences small. Sky conditions were categorized from the video recordings as sunny, partly cloudy or cloudy (ca. 0-2, 3-5, 6-8 okta cloud cover, respectively).

\section{Performance quantification}

We quantified different aspects of performance in a variety of ways, both by performing computations on the trajectory data and by direct observation of the RSV images (Fig. 1). Birds were categorized into seven flight behaviour categories by observation of the video recordings (e.g. Movie 1): flapping, gliding with extended wings, gliding with highly swept wings, wings folded, gliding with a high dihedral, inverted flight or behaviour not visible (because of blurred image or very distant bird). Only birds performing at least one full downstroke and upstroke cycle were categorized as flapping, and birds did occasionally perform short manoeuvring wing movements during gliding.

A variety of kinematic metrics were calculated, as shown below.

Flight speed in the ground reference frame $\left(\mathrm{m} \mathrm{s}^{-1}\right)$ :

$$
s=|\mathbf{v}|,
$$

where $\mathbf{v}$ is the velocity vector $(\dot{X}, \dot{Y}, \dot{Z})$.
Flight speed in the air reference frame $\left(\mathrm{m} \mathrm{s}^{-1}\right)$ :

$$
U_{\mathrm{e}}=\left|\mathbf{v}_{\mathrm{a}}\right|=|\mathbf{v}-\mathbf{A}| \sqrt{\left(\frac{\rho}{\rho_{0}}\right)},
$$

where $\mathbf{v}_{\mathrm{a}}$ is the velocity vector in the air reference frame computed by subtracting wind speed vector $\mathbf{A}$, determined from the helium balloon tracking tests, from $\mathbf{v}$ and, for $\mathbf{v}_{\mathrm{a}, \mathrm{e}}$, by correcting for observed air density by multiplying by $\sqrt{ }\left(\rho / \rho_{0}\right)$ where $\rho$ is air density and $\rho_{0}$ is standard air density.

Radius of curvature of turns (m):

$$
R=\frac{\left|\mathbf{v}_{\mathrm{a}}\right|^{3}}{\sqrt{\left|\mathbf{v}_{\mathrm{a}}\right|^{2}|\mathbf{a}|^{2}-\left(\mathbf{v}_{\mathrm{a}} \cdot \mathbf{a}\right)^{2}}},
$$

where $\mathbf{a}$ is the air reference frame acceleration vector $(\ddot{X}, \ddot{Y}, \ddot{Z})$.

Mass-specific centripetal force (i.e. centripetal acceleration) $\left(\mathrm{m} \mathrm{s}^{-2}\right)$ :

$$
F=\frac{\left|\mathbf{v}_{\mathrm{a}}\right|^{2}}{R} .
$$

Mass-specific rate of change in potential energy $\left(\mathrm{W} \mathrm{kg}^{-1}\right)$ :

$$
P_{\mathrm{p}}=g \dot{Z}_{\mathrm{e}},
$$

where $g$ is the magnitude of gravitational acceleration. Note that we measured horizontal wind speed and direction only, so $\mathbf{A}$ has no vertical component and values from the ground and air reference frames are equal.

Mass-specific rate of change in kinetic energy $\left(\mathrm{W} \mathrm{kg}^{-1}\right)$ :

$$
P_{\mathrm{k}}=\mathbf{v}_{\mathrm{a}, \mathrm{e}} \cdot \mathbf{a}_{\mathrm{e}} .
$$

Mass-specific (air frame of reference) kinematic power $\left(\mathrm{W} \mathrm{kg}^{-1}\right)$ :

$$
P=P_{\mathrm{p}}+P_{\mathrm{k}}
$$


Note that Eqns 7-10 all produce mass-specific outputs because the body masses of the individual swifts are unknown. For example, Eqn 7 might be written as:

$$
\frac{F}{m}=\frac{\left|\mathbf{v}_{\mathrm{a}}\right|^{2}}{R},
$$

with $m$ denoting mass, but because all quantities here are mass specific we omit $m$ to simplify the expressions. We computed freeflight glide polars from $U_{\mathrm{e}}$ and $P$ by fitting coefficients to the following equation (Azuma, 1992):

$$
\dot{Z}_{\mathrm{fit}}=\frac{P}{g}=k_{1} \frac{1}{2} \rho_{0} S\left(U_{\mathrm{e}}\right)^{3}+k_{2} \frac{2(m g)^{2}}{\rho_{0} S U_{\mathrm{e}}},
$$

where $\dot{Z}_{\text {fit }}$ is the sinking rate that expends potential energy at the same rate as the overall kinematic power $P, k_{1}$ is a coefficient for parasite and profile power and $k_{2}$ is the induced power coefficient. Literature values of $0.0171 \mathrm{~m}^{2}$ and $0.043 \mathrm{~kg}$ were used for $S$ (wing area) and $m$ (body mass), respectively (Hedenström and Rosén, 2001).

\section{Sharp turns}

We identified short time scale sharp turns with two methods. The first method identified a sharp turn as a point with centripetal force $F$ greater than or equal to the 95 th percentile for $F$ in the whole dataset (i.e. greater than $1.10 \mathrm{~g}$ ), expanded to reach the local minima in $F$ before and after the local maximum $F$ event; events with shared start and end points were combined. The second method used a similar approach applied to the radius of curvature, $R$, identifying sequences with $R$ less than or equal to the 5 th percentile in the whole dataset (i.e. less than $4.86 \mathrm{~m}$ ) and expanding to the adjacent local maxima in $R$. The underlying $6 \mathrm{~Hz}$ sample frequency of our recordings limits the minimum duration of the turn events identified with this method to $0.33 \mathrm{~s}$. These sharp turns were then characterized by whole-turn values for other kinematic metrics; statistical comparisons were made between the average values during turning and the average values for the whole track.

\section{Turning behaviour}

The swifts exhibited a variety of longer time scale turning behaviours during these recordings and it became apparent during analysis that different behaviours had different biomechanical properties, e.g. different average airspeeds. To better examine these differences, flight trajectories were categorized on a per data point basis (i.e. at $6 \mathrm{~Hz}$ ) into circling, meandering and straight flight turning behaviour groups. Turning category was determined by considering the change in ground heading in a time interval, defined as the time required to fly a $20 \mathrm{~m}$ radius circle at the mean airspeed for the entire dataset (i.e. $13 \mathrm{~s}$ ), centred on the data point in question. An overall change in heading during this interval consistent with continuously completing $20 \mathrm{~m}$ radius (or smaller) circles at the bird's actual airspeed was categorized as circling flight. Cumulative changes in heading consistent with circles of radius greater than $20 \mathrm{~m}$ but less than $40 \mathrm{~m}$ were categorized as meandering flight; all other data were categorized as straight flight. The temporal and spatial scales were determined by examination of tracks such as that in Fig. S1 which exhibit apparent thermal soaring; in these cases, the circle radii are smaller than described above but bird airspeeds are also lower than the whole dataset average. Our definition of turning considers the trajectory only, meaning that faster flying birds would need to generate larger centripetal forces to satisfy the circling flight criteria. Thus, we expect there to be differences in average flight speed or flapping effort among the three categories. Categorization requires continuous data and thus was performed on the interpolated trajectories but subsequent analysis was on the uninterpolated portions only.

\section{Data sampling}

The data resulting from the flight trajectory recordings take the form of an auto-correlated time series with large variation in airspeed, elevation, turning behaviour and many other parameters. To capture the range of behaviours while avoiding pseudo-replication, we sampled the time series at the interval required for the autocorrelation in $P$ to become less than or equal to 0 ; this was a median of $0.83 \mathrm{~s}$ with a range from 0.33 to $4.50 \mathrm{~s}$. Linear models applied to sampled data also typically included an individual intercept for each bird recording to accommodate persistent per-bird differences in performance or behaviour; descriptive statistics were calculated from the means (or medians, etc.) of individual recordings. Linear mixed-effects models were computed in $\mathrm{R}$
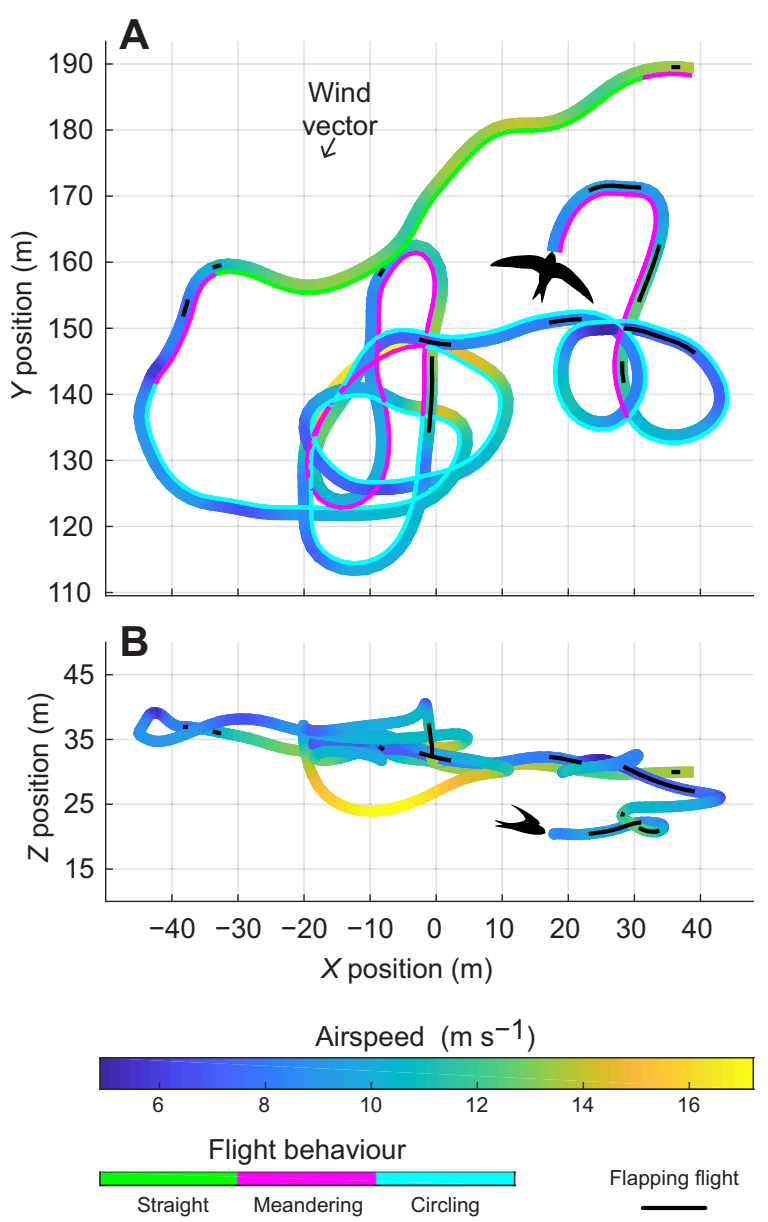

Fig. 2. Example trajectory. A sample common swift flight track from the dataset, $64 \mathrm{~s}$ long with an average equivalent airspeed of $10.1 \mathrm{~m} \mathrm{~s}^{-1}$, shown in (A) overhead and $(B)$ side views as ground reference frame position. The swift silhouette (not to scale) marks the start in each case. Flight speed is shown by colour in the wider ribbon, with a black line overlaid when the bird was flapping, $13 \%$ of the time in the data shown here. Non-flapping time was spent in extended wing gliding ( $80 \%$ ) or highly swept wing gliding $(7 \%)$ of the recording shown here. The thin ribbon in A denotes the classification as straight, meandering or circling flight. Note that $U$-turns such as those near the centre of $A$, rarely met our definition of circling because they did not contain a full 360 deg change in heading. The wind vector measured for this recording is shown in $\mathrm{A}$; wind speed was $2.4 \mathrm{~m} \mathrm{~s}^{-1}$. 

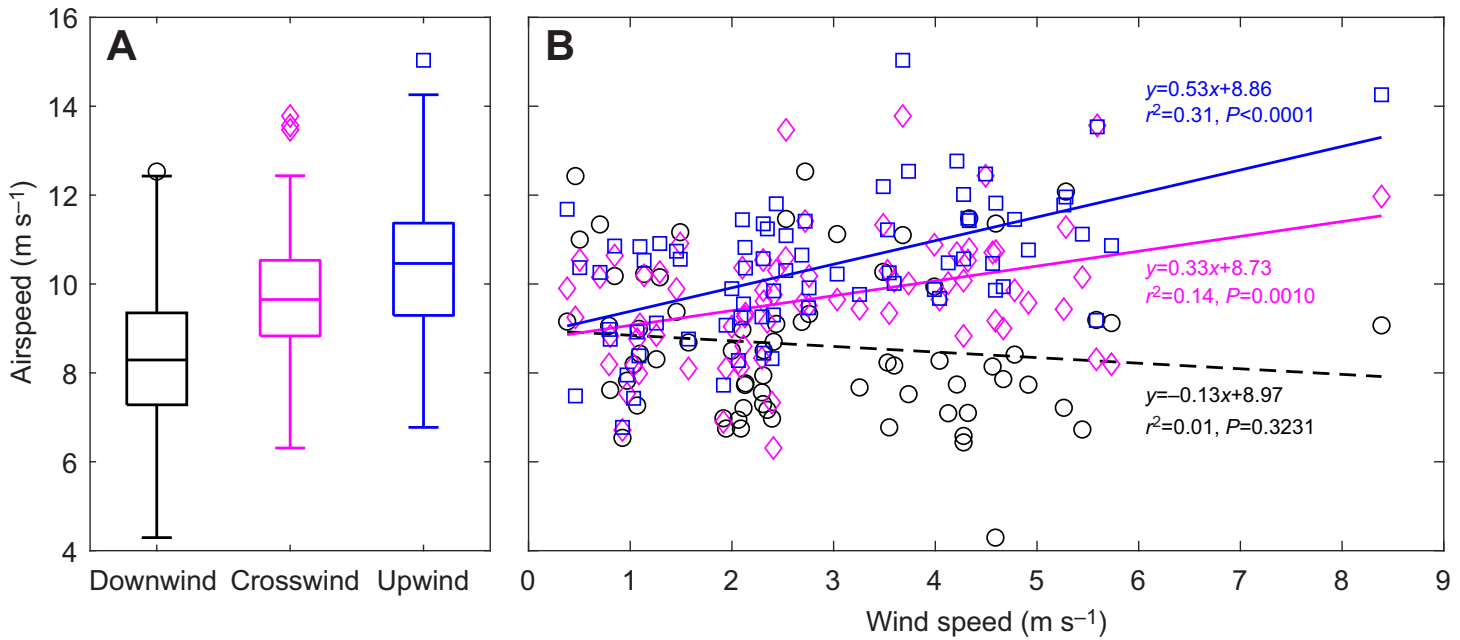

Fig. 3. Airspeed versus wind direction. Swift airspeed varied with wind speed and direction as shown by computing the mean airspeed of each swift track when the bird was flying in three equal-size directional bins with regard to the wind vector. (A) Box plots showing the median, 25th and 75th percentiles, data range excluding outliers (whisker) and outliers (symbols). Outliers are more than 1.5 interquartile range (IQR) distant from the 25th or 75th percentile. All three groups differ from one another (Tukey-Kramer tests following single-factor ANOVA, downwind-crosswind $P=0.0001$, downwind-upwind $P<0.0001$, crosswind-upwind $P=0.0212$; sample sizes are 67,72 and 72 tracks). (B) The effect of wind speed on airspeed within each of these bins; colour and shape codes match those in $A$.

3.0.2 using the nlme package; all other computations were performed in MATLAB r2017b (The Mathworks, Natick, MA, USA).

\section{RESULTS}

The RSV recordings of common swift foraging flights yielded 73 smoothed flight tracks of up to $312 \mathrm{~s}$ (minimum $25 \mathrm{~s}$, median $58 \mathrm{~s}$ ) duration in which the bird flew along a path of up to $2399 \mathrm{~m}$. The birds used a variety of flight speeds and behaviours and a mix of flapping and gliding during these recordings (Fig. 2). The mean ( \pm s.d.) equivalent airspeed among all tracks was $9.71 \pm 1.36 \mathrm{~m} \mathrm{~s}^{-1}$ (i.e. a mean of within-recording means); median centripetal force among tracks was 0.49 body weights with an inter-quartile range (IQR) of 0.12, computed from the median of each track. Median radius of curvature among tracks was $19.78 \mathrm{~m}$ (IQR of 8.65), computed from the median of each track. Median wind speed for the recordings was $2.44 \mathrm{~m} \mathrm{~s}^{-1}$ (IQR of 2.68); maximum wind speed was $8.39 \mathrm{~m} \mathrm{~s}^{-1}$. Of the 73 recordings, 37 were categorized as sunny sky conditions, 26 as partly sunny and 10 as cloudy.

\section{Flight speed versus wind direction}

We examined the relationship between flight direction with respect to the wind and airspeed by dividing the data points into one of three directional bins based on the angle between the bird's instantaneous 2D ground heading and the wind vector - downwind (0-60 deg angle), crosswind (60-120 deg) and upwind (120-180 deg) - and computing a mean equivalent airspeed for each bin (Fig. 3). All bins differed from one another by mean airspeed; the crosswind and upwind groups also exhibited an increase in speed linearly proportional to the wind speed, with similar intercepts and respective slopes of 0.33 and 0.53 . Downwind flights exhibited a non-significant decrease in airspeed with wind speed.

\section{Characteristics of straight, meandering and circling flight}

As anticipated, the flight behaviour groups of straight, meandering and circling flight exhibited statistically significant differences in many other aspects of flight biomechanics, shown in Table 1 as the mean \pm s.d. of track means (or median and IQR of track medians for quantities such as $R$ that are expected to produce skewed

Table 1. Characteristics of turning behaviour categories

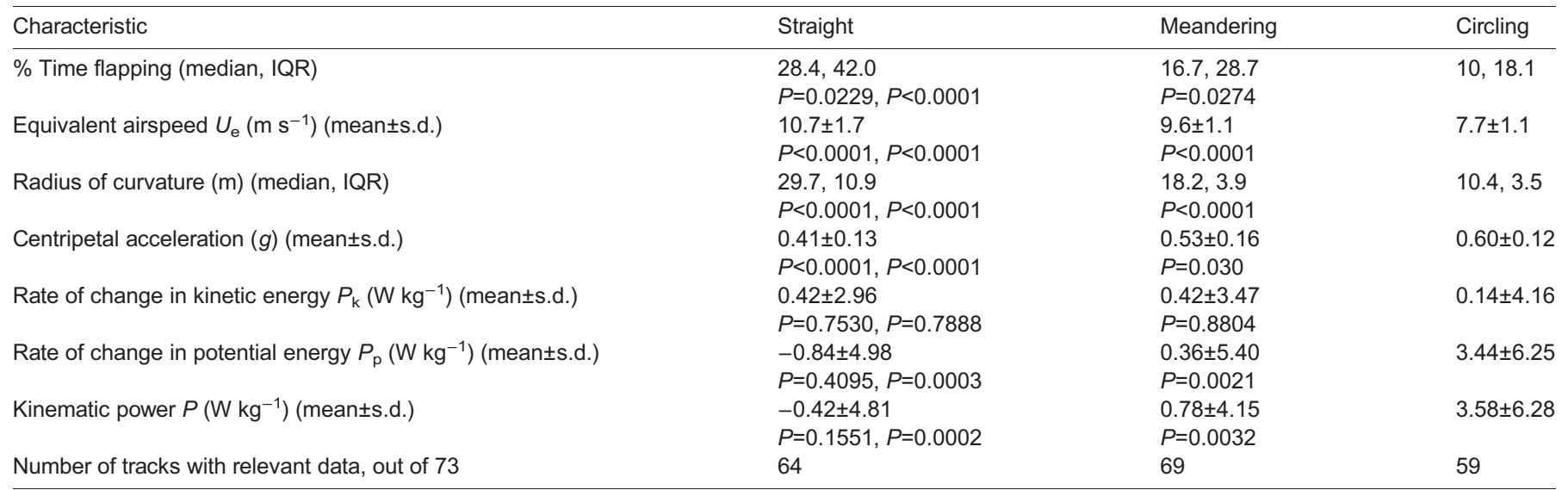

$P$-values are the result of a Tukey-Kramer post hoc test following a single-factor ANOVA. Comparisons in the Straight column are straight:meandering, straight: circling; those in the Meandering column are meandering:circling. 
Table 2. Characteristics of turning behaviour categories, gliding flight

\begin{tabular}{|c|c|c|c|}
\hline Characteristic & Straight & Meandering & Circling \\
\hline Equivalent airspeed $U_{\mathrm{e}}\left(\mathrm{m} \mathrm{s}^{-1}\right)$ (mean \pm s.d.) & $\begin{array}{l}10.7 \pm 1.6 \\
P<0.0001, P<0.0001\end{array}$ & $\begin{array}{l}9.6 \pm 1.1 \\
P<0.0001\end{array}$ & $7.6 \pm 1.2$ \\
\hline Radius of curvature (m) (median, IQR) & $\begin{array}{l}28.5,11.6 \\
P<0.0001, P<0.0001\end{array}$ & $\begin{array}{l}17.4 \pm 4.8 \\
P<0.0001\end{array}$ & $9.9 \pm 3.7$ \\
\hline Centripetal acceleration $(g)$ (mean \pm s.d.) & $\begin{array}{l}0.43 \pm 0.14 \\
P<0.0001, P<0.0001\end{array}$ & $\begin{array}{l}0.56 \pm 0.20 \\
P=0.1404\end{array}$ & $0.62 \pm 0.14$ \\
\hline Rate of change in kinetic energy $P_{\mathrm{k}}\left(\mathrm{W} \mathrm{kg}^{-1}\right)$ (mean \pm s.d.) & $\begin{array}{l}0.41 \pm 5.38 \\
P=0.3132, P=0.2113\end{array}$ & $\begin{array}{l}1.34 \pm 5.43 \\
P=0.7513\end{array}$ & $1.57 \pm 6.69$ \\
\hline Rate of change in potential energy $P_{\mathrm{p}}\left(\mathrm{W} \mathrm{kg}^{-1}\right)$ (mean $\left.\pm \mathrm{s} . \mathrm{d}.\right)$ & $\begin{array}{l}-3.06 \pm 6.22 \\
P=0.8960, P=0.0037\end{array}$ & $\begin{array}{l}-2.85 \pm 7.34 \\
P=0.0029\end{array}$ & $1.13 \pm 8.04$ \\
\hline Kinematic power $P\left(\mathrm{~W} \mathrm{~kg}^{-1}\right)$ (mean \pm s.d.) & $\begin{array}{l}-2.64 \pm 5.81 \\
P=0.3173, P<0.0001\end{array}$ & $\begin{array}{l}-1.51 \pm 5.68 \\
P<0.0001\end{array}$ & $2.70 \pm 6.85$ \\
\hline Number of tracks with relevant data, out of 73 & 63 & 69 & 59 \\
\hline
\end{tabular}

$P$-values are the result of a Tukey-Kramer post hoc test following a single-factor ANOVA. Comparisons in the Straight column are straight:meandering, straight: circling; those in the Meandering column are meandering:circling.

distributions). In most cases, the meandering flight category produced quantitative results intermediate between straight and circling flight. Although the group definitions do not make direct use of instantaneous radius of curvature, it is unsurprising that the groups differed in this regard, with the median instantaneous $R$ ranging from $29.7 \mathrm{~m}$ (straight) to $10.4 \mathrm{~m}$ (circling). As noted in Materials and Methods, our definition of the turning behaviour groups also makes it likely that they will exhibit different average airspeeds, and average $U_{x y, \mathrm{e}}$ ranged from $10.9 \mathrm{~m} \mathrm{~s}^{-1}$ (straight) to $7.7 \mathrm{~m} \mathrm{~s}^{-1}$ (circling). These trends in speed and radius of curvature potentially reduce variation in centripetal acceleration $F$ among categories, but statistically significant variation was still present, with the greatest $F$ occurring in circling flight.

When averaged over the whole set of tracks (Table 1), the rate of change in kinetic energy was close to zero for all turning behaviour categories. The same was true of potential energy in straight and meandering flight, but birds in the circling category gained potential energy at the average rate of $3.44 \mathrm{~W} \mathrm{~kg}^{-1}$, consistent with a constant upward velocity of approximately $0.35 \mathrm{~m} \mathrm{~s}^{-1}$. Birds in all groups spent less than half their time flapping, up to $28 \%$ of the time in straight flight and as little as $10 \%$ of the time in circling flight. The vast majority of non-flapping time was spent in extended wing gliding in all behavioural groups, and sufficient data exist to extend the Table 1 results to straight, meandering and circling flight with extended wing gliding only (Table 2).

Differences among turning behaviour groups were largely unaffected by restricting the analysis to extended wing gliding only (Table 2). However, $P_{\mathrm{p}}$ and $P$ were reduced in all flight groups.
On average, $P$ was negative for gliding-only straight and meandering flight, but even in these cases it corresponded to a sinking rate of only 0.27 and $0.15 \mathrm{~m} \mathrm{~s}^{-1}$, respectively.

\section{Characteristics of flapping and gliding flight}

Among all tracks, the swifts spent 23\% (median, IQR 24\%) of the time in flapping flight and $74 \%$ (median, IQR $21 \%$ ) in extended wing gliding. Flapping bouts were $0.68 \mathrm{~s}$ (median, IQR $0.33 \mathrm{~s}$ ) long while gliding bouts (with extended, swept, tucked or high dihedral wing position) were $1.58 \mathrm{~s}$ (median, quartiles 1.00 and $2.84 \mathrm{~s}$ ) long. Table 3 explores differences in mean and median flight performance quantities for these two categories and reveals that, unsurprisingly, flapping flight resulted in an increase in potential and total energy (but not kinetic energy) compared with gliding. However, gliding itself was nearly energetically neutral in terms of $P$, with the mean of track means not significantly different from zero ( $t$-test, $P=0.0775)$ and corresponding to a sinking rate of less than $0.10 \mathrm{~m} \mathrm{~s}^{-1}$.

Other flight behaviours were infrequent. Gliding with highly swept wings accounted for $2.99 \%$ of all positions, while folded wings (equivalent to bounding flight) represented $0.58 \%$ of positions. Both behaviours were associated with a strong negative vertical acceleration $\left(-4.9 \pm 3.5 \mathrm{~m} \mathrm{~s}^{-2}\right.$ and $-5.9 \pm 2.9 \mathrm{~m} \mathrm{~s}^{-2}$, respectively; mean \pm s.d. computed from all instances of these behaviours due to their rarity), approaching or sometimes exceeding free-fall acceleration ( $\leq-9.8 \mathrm{~m} \mathrm{~s}^{-2}$ for $0.18 \%$ of all positions), as the birds converted forward motion into vertical motion. Highly swept or folded wings were mainly observed during short aerobatic manoeuvres that could be interpreted as insect capture or in-flight

Table 3. Characteristics of flapping and gliding flight

\begin{tabular}{|c|c|c|c|}
\hline Characteristic & Flapping & Extended wing gliding & Paired $t$-test result \\
\hline$\%$ Time flying straight (median, IQR) & 49,55 & 26,38 & $P<0.0001$ \\
\hline$\%$ Time meandering (median, IQR) & 35,33 & 38,24 & $P=0.4818$ \\
\hline$\%$ Time circling (median, IQR) & 9,31 & 25,39 & $P<0.0001$ \\
\hline Radius of curvature $(\mathrm{m})$ (median, IQR) & $25.7,13.9$ & $16.8,8.6$ & $P<0.0001$ \\
\hline Centripetal acceleration $(g)$ (mean \pm s.d.) & $0.42 \pm 0.10$ & $0.54 \pm 0.14$ & $P<0.0001$ \\
\hline Rate of change in kinetic energy $P_{\mathrm{k}}\left(\mathrm{W} \mathrm{kg}^{-1}\right)($ mean \pm s.d.) & $\begin{array}{l}-0.11 \pm 5.44 \\
P=0.8666\end{array}$ & $\begin{array}{l}0.83 \pm 2.13 \\
P=0.0014\end{array}$ & $P=0.2243$ \\
\hline Kinematic power $P\left(\mathrm{~W} \mathrm{~kg}^{-1}\right)$ (mean \pm s.d. $)$ & $\begin{array}{l}6.85 \pm 5.71 \\
P<0.0001\end{array}$ & $\begin{array}{l}-0.84 \pm 4.00 \\
P=0.0775\end{array}$ & $P<0.0001$ \\
\hline Number of tracks with relevant data, out of 73 & 72 & 73 & - \\
\hline
\end{tabular}


preening (de Margerie et al., 2018). Highly swept wings were also repeatedly observed when the bird dived toward its nest at the end of a foraging flight, attaining equivalent airspeeds up to $22.9 \mathrm{~m} \mathrm{~s}^{-1}$. High
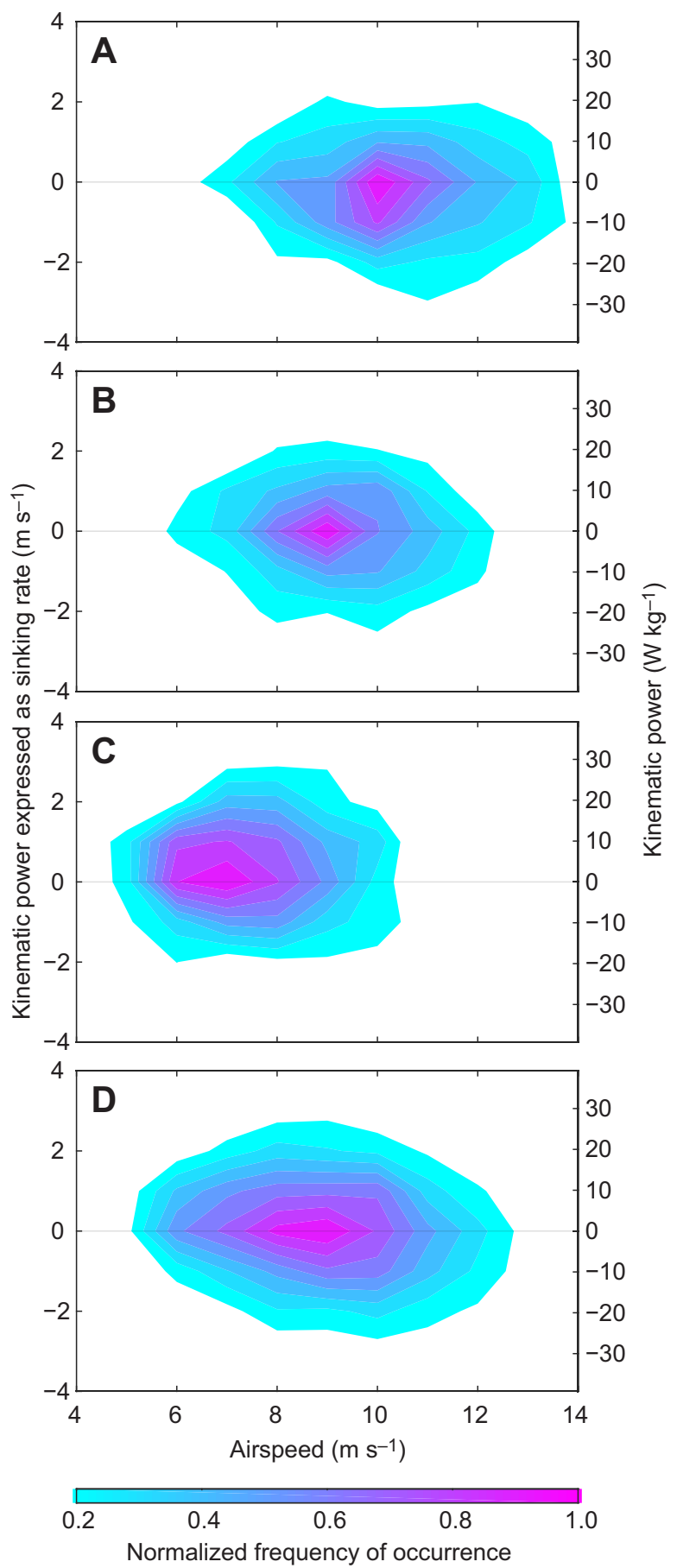

Fig. 4. Kinematic power versus turning behaviour. The relative frequency of occurrence of different airspeed and kinematic power combinations for sub-sampled gliding track data categorized as (A) straight flight, (B) meandering flight, $(C)$ circling flight and $(D)$ all categories. Kinematic power, i.e. the rate of change in kinetic and potential energy, is converted to a sinking rate; positive sinking rate corresponds to energy gain. Plots were generated by summing the frequency of occurrence of data in $1.0 \mathrm{~m} \mathrm{~s}^{-1} 2 \mathrm{D}$ bins, normalizing by dividing by the most populous bin, then finding continuous contours for each level listed in the colour key. Note the two trends in A-C toward a reduced airspeed and positive sinking rate (i.e. energy gain). Total sample sizes for each category are 958, 1493, 1296 and 4315, respectively. dihedral gliding, inverted flight and not visible flight behaviour were extremely rare occurrences, accounting for only $0.2 \%$ of positions.

\section{Characteristics of sharp turns}

As described in Materials and Methods, we used two methods for identifying sharp turns: local maxima in centripetal force or local minima in the radius of curvature (Table 4). In both cases the turns were mostly non-flapping phenomena, and the percentage of time spent flapping during both turn types was less than that for the whole dataset and in both cases the average duration of a whole turn was about $2 \mathrm{~s}$. In most other respects, these two definitions produced distributions with different characteristics. For example, sharp turns by radius of curvature had an elevated occurrence of swept wing gliding as compared with the whole dataset while sharp centripetal force turns did not. Sharp centripetal force turns were also found in all turning behaviours (straight, meandering circling) whereas sharp radius of curvature turns were more often found in circling flight. In other respects, the different criteria produced output in line with expected interactions between the behavioural definition and the simple mechanics of turning. For example, sharp centripetal force turns occurred at higher than average flight speeds while sharp radius of curvature turns occurred at slower than average speeds.

\section{Glide polars from field recordings}

The results described above focus on the mean or median result for each track. However, extracting glide polars from these recordings requires quantification of flight performance over a wide range of speeds and thus inclusion of data from within each track, subsampled as described in Materials and Methods. Fig. 4 shows the combined results for $P$ (expressed as the power-equivalent sinking rate) for all tracks. As indicated by mean track results for kinematic power $P$ in gliding flight presented in Table 2 and described above, the swifts appear to make use of environmental energy during much of the circling behaviour, probably through use of thermals as indicated by the positive $P$ and rising circle trajectories seen in some recordings (e.g. Fig. S1). Fig. 4 reveals that gliding flight in all turning behaviour categories contains a substantial fraction or even outright majority of samples exhibiting positive power, probably due to environmental energy extraction from thermals, gusts and other aerial features. These data cannot be used for fitting a glide polar as one of the underlying assumptions is that all the energy needed to overcome drag and keep the bird aloft comes from potential energy, not the environment. Data with substantial acceleration, either linear or centripetal, also cannot be used for deriving a glide polar as the additional lift required for acceleration will increase induced drag costs. Taking these requirements into consideration, we selected only data points with negative $P$ and acceleration less than $0.5 \mathrm{~g}$ and then used a linear mixed-effects model to fit the sub-sampled track data, with track ID as a random effect, to Eqn 11, for each turning behaviour category and for all data; the results are shown in Fig. 5. The straight, meandering and circling data all produced overall similar glide polars and were generally within the $95 \%$ confidence interval of the curve for all data meeting the kinematic and acceleration criteria. The best-fit glide polar to all data identified a minimum sink rate of $0.75 \mathrm{~m} \mathrm{~s}^{-1}$ at an airspeed (i.e. maximum duration speed) of $6.9 \mathrm{~m} \mathrm{~s}^{-1}$ and a maximum glide distance speed of $9.0 \mathrm{~m} \mathrm{~s}^{-1}$; the best lift to drag ratio was 10.5 .

\section{DISCUSSION}

Our 3D flight trajectories and behavioural observations of wild, freely behaving common swifts foraging near their nests provide 
Table 4. Characteristics of sharp turns

\begin{tabular}{|c|c|c|}
\hline Characteristic & Centripetal force turns & Radius of curvature turns \\
\hline Number of tracks with data, out of 73 & 61 & 52 \\
\hline Event duration (s) (median, IQR) & $2.07,0.62$ & $2.08,0.74$ \\
\hline Net change in 2D heading (deg) (mean \pm s.d.) & $95.7 \pm 32.5$ & $89.9 \pm 29.4$ \\
\hline Median radius of curvature $(\mathrm{m})$ (median, IQR) & $13.1,7.0 P<0.0001$ & $8.1,3.2 P<0.0001$ \\
\hline Minimum radius of curvature $(\mathrm{m})$ (median, IQR) & $6.4,3.3$ & $3.5,1.0$ \\
\hline Centripetal acceleration $(g)$ (median, IQR) & $0.80,0.16 P<0.0001$ & $0.64,0.24 P<0.0001$ \\
\hline Max. centripetal acceleration $(g)$ (mean \pm s.d.) & $1.34 \pm 0.14$ & $1.11 \pm 0.36$ \\
\hline Kinematic power $P\left(\mathrm{~W} \mathrm{~kg}^{-1}\right)$ (mean \pm s.d.) & $-1.2 \pm 7.6 P=0.0473$ & $0.2 \pm 7.7 P=0.5479$ \\
\hline Airspeed $\left(\mathrm{m} \mathrm{s}^{-1}\right)($ mean \pm s.d. $)$ & $9.9 \pm 1.7 P=0.3831$ & $7.4 \pm 1.4 P<0.0001$ \\
\hline$\%$ Time in extended wing gliding (mean \pm s.d.) & $76.6 \pm 21.0 P=0.0011$ & $77.2 \pm 17.3 P=0.1581$ \\
\hline$\%$ Time flapping (mean \pm s.d.) & $19.4 \pm 21.8 P=0.0002$ & $12.6 \pm 13.3 P<0.0001$ \\
\hline$\%$ Time in swept wing gliding (mean \pm s.d.) & $3.0 \pm 6.0 P=0.8721$ & $7.5 \pm 13.3 P=0.0068$ \\
\hline$\%$ Time in straight, meandering and circling flight (mean for each case) & $23,40,37 P=0.0003,0.4006,0.0137$ & $4,27,68 P<0.0001,<0.0001,<0.0001$ \\
\hline
\end{tabular}

Values are the mean (or median) of per-track mean or median values. $P$-values in columns are the result of paired $t$-tests comparing turning quantities with wholetrack quantities.

an opportunity to examine hypotheses relating to how birds apply their underlying flight performance capabilities in different environmental and behavioural contexts. We consider predictions related to airspeed versus wind direction, manoeuvrability, glide performance and environmental energy extraction, in that order.

\section{Flight speed versus wind direction}

Migratory and commuting birds are known to adjust their airspeed in response to wind, sometimes matching predictions for optimal ground distance transport, increasing airspeed when flying into the wind and decreasing airspeed when flying downwind (e.g. Hedenström et al., 2002; Kogure et al., 2016; Wakeling and Hodgson, 1992). We hypothesized that the swifts would not follow this pattern when foraging on small insect prey more than $10 \mathrm{~m}$ above the ground because these prey are tied to the air, not the ground, reference frame. However, we found that the swifts did adjust their airspeed in response to flight direction relative to the wind, with a significant effect of wind speed on airspeed for crosswind and upwind flights (Fig. 3B). The magnitude and direction of the effects is also consistent with theoretical changes to

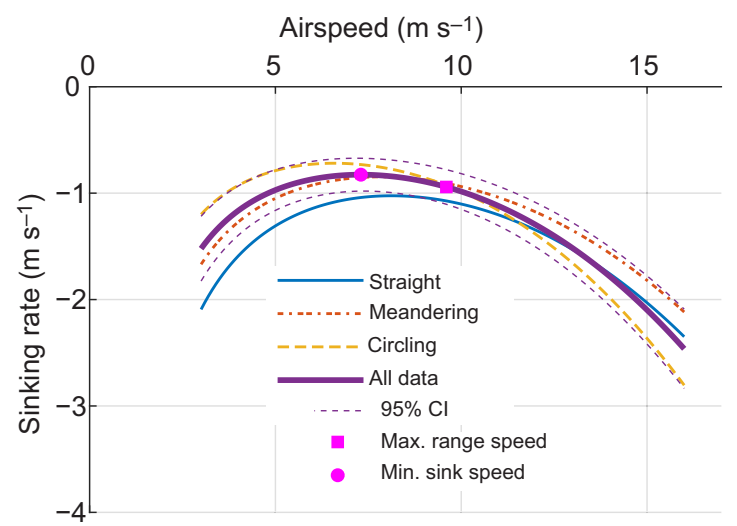

Fig. 5. Glide polar. Polar plots derived from the extended-wing gliding portion of the dataset, restricted to data with negative kinematic power and acceleration $<0.5 \mathrm{~g}$, resulting in 312, 304 and 144 data points for the straight, meandering and circling categories respectively. Curves were fits to Eqn 11 using a linear mixed effects model with a random effect for individual tracks. All coefficients were highly significant with $P<0.0001$. For the all-data case (i.e. data from all three turning behaviours), the maximum duration speed was $6.9 \mathrm{~m} \mathrm{~s}^{-1}$ with a sink rate of $0.75 \mathrm{~m} \mathrm{~s}^{-1}$. The maximum range speed was $9.0 \mathrm{~m} \mathrm{~s}^{-1}$ and the best lift to drag ratio was 10.5 . $\mathrm{Cl}$, confidence interval. airspeed to achieve maximum range in different wind conditions (Fig. S2). For example, for flight into an $8 \mathrm{~m} \mathrm{~s}^{-1}$ headwind, the glide polar calculated from the swift data produces a predicted maximum range airspeed of $13.8 \mathrm{~m} \mathrm{~s}^{-1}$ (compared with $9.0 \mathrm{~m} \mathrm{~s}^{-1}$ with no wind) and we observed a speed of $13.1 \mathrm{~m} \mathrm{~s}^{-1}$ (Fig. 3B). The swifts did not significantly decrease airspeed when flying downwind; this may be because the expected changes in airspeed are smaller and thus more difficult to detect - based on the glide polar, the predicted decrease in airspeed for flight with an $8.0 \mathrm{~m} \mathrm{~s}^{-1}$ tailwind is only $1.1 \mathrm{~m} \mathrm{~s}^{-1}$ (Fig. S2), a good match to the $1.07 \mathrm{~m} \mathrm{~s}^{-1}$ reduction implied by the non-significant regression slope in Fig. 3B for downwind flights. Note that because we base the analysis only on cases close to a perfect headwind or tailwind, a 2D analysis of wind effect (Shamoun-Baranes et al., 2007) is unnecessary. Thus, swifts appear to prioritize their ground reference frame position over aerial foraging, probably because of the presence of nestlings at a fixed ground frame position (central-place foraging). Alternatively, our original assumption that the insect prey are tied to the air, not the ground, although well supported by radar evidence on smaller insects (Geerts and Miao, 2005; Wainwright et al., 2017), may be partly incorrect for larger, faster prey species.

\section{Sharp turns and manoeuvring performance}

We hypothesized that although swifts are probably capable of highperformance manoeuvres, these might not be a common feature of foraging flight given the expected difference in flight speed between swifts and their small insect prey. This hypothesis was well supported, at least for high centripetal force turns, i.e. turns that contained a peak centripetal force $F$ greater than the 95 th percentile for $F$ in the dataset as a whole. The average maximum $F$ in these turns was only $1.38 \mathrm{~g}$, in comparison to the nearly $8 \mathrm{~g}$ turn recorded during cliff swallow intraspecific chases (Shelton et al., 2014) and the nearly $7 \mathrm{~g}$ turn recorded from foraging barn swallows (Warrick et al., 2016). Barn swallows were also found to enhance flight manoeuvres with flapping and we hypothesized that the swifts would do the same. This hypothesis was not supported; flapping was less common during swift turns than in the swift dataset as a whole, where it was already uncommon. The barn swallow results indicated that modelling flapping manoeuvrability (often termed facultative manoeuvrability), might be critical to understanding barn swallow ecomorphology, but the opposite appears to be true of swifts. However, an existing model of swift manoeuvrability (Lentink et al., 2007) found that many aspects of manoeuvrability are maximized at higher flight speeds beyond those characteristic of 
either turns (Table 4) or the dataset as a whole (Table 2). Birds may also modulate their intrinsic manoeuvrability by changing wing morphology and we did find that highly swept wing postures were more common during vertically oriented turns defined by sharp radius of curvature where the swifts appear to reduce lift, benefiting from gravity during the turn.

\section{Field glide polars versus wind tunnel results}

Following an extensive selection procedure to remove data exhibiting either energy gain $(P>0)$ or large accelerations $(|(\ddot{X}, \ddot{Y}, \ddot{Z})|>g / 2)$, we converted all changes in potential or kinetic energy to an equivalent sinking rate and fitted a glide polar (Fig. 5). The data selection procedure reduced the dataset to only $20 \%$ of its original size. It also produced a glide polar that was a close match to previously reported results from wind tunnel testing of live birds (Henningsson and Hedenström, 2011) and of prepared wings (Lentink et al., 2007). As summarized in Table 5, the values measured from freely behaving wild birds are similar to those from wind tunnels with the best agreement among the studies in the minimum sink rate and maximum lift to drag ratio, but slightly more variation in the exact speeds at which those were reached. Our freeflight results typically show the slowest maximum duration speed and a greater range between the maximum duration and maximum range speeds, suggesting a slightly more varied performance envelope than was revealed by wind tunnel studies involving fewer birds. However, the discrepancies between this study and wind tunnel results all fall within the $95 \%$ confidence interval curves for the free-flight glide polar.

Despite the general agreement between the free-flight and wind tunnel data, it remains possible that our data selection procedure affected our results. Specifically, by removing all positive power data points, we may bias the analysis by removing cases where the birds benefit from upward air movement but retaining cases where downward air movement or turbulence negatively affects performance. However, we may also retain cases where the birds benefit from upward air movement but the magnitude of the benefit is not large enough to make the kinematic power measure positive. Finally, the glide polar sets an upper bound to performance, but birds may occasionally find real-world conditions best served by submaximal performance, e.g. increasing drag while foraging in a thermal so as to avoid gaining elevation. The frequency and magnitude of these different possible effects is unknown and while close agreement with wind tunnel studies suggests that they are small, the potential bias leaves the possibility that actual field glide performance differs from what is reported here. Finally, because the field glide polar is similar to that from wind tunnel studies, other findings from this work that refer to the polar would be equally well supported by referring to wind tunnel polars instead.

\section{Environmental energy extraction}

We hypothesized that foraging swifts would make use of environmental energy to help meet the energetic requirements for flight based on the use of environmental energy in barn swallows, another species of coursing aerial insectivore. The swift data strongly support this hypothesis, to the extent that during the extended wing gliding flight that makes up the majority of observed behaviour, the birds lost kinetic and potential energy at the statistically insignificant rate of $-0.83 \mathrm{~W} \mathrm{~kg}^{-1}$, equivalent to a sinking rate of less than $0.1 \mathrm{~m} \mathrm{~s}^{-1}$ (Table 3 ). The average rate of energy change during gliding varied with longer time scale turning behaviour (Table 2), ranging from a gain of $2.70 \mathrm{~W} \mathrm{~kg}^{-1}$ when circling to $-2.64 \mathrm{~W} \mathrm{~kg}^{-1}$ when flying straight. This suggests that thermal soaring is a part of the energy extraction equation, but even straight gliding flight loses energy at less than one-third the rate predicted by the glide polar. Thus, swifts in straight flight appear to be adept at taking momentary advantage of thermals as they pass through them or possibly using wind gusts or other local gradients. This possibility is further supported by comparing straight, extended wing gliding during cloudy days when thermals should be less prominent with data from sunny days. While only 10 tracks included straight glide data in these conditions, the average rate of energy change was $-4.11 \pm 4.79 \mathrm{~W} \mathrm{~kg}^{-1}$ (mean \pm s.d.) at an average flight speed of $10 \mathrm{~m} \mathrm{~s}^{-1}$ where the glide polar predicts a rate of $-9.5 \mathrm{~W} \mathrm{~kg}^{-1}$.

Common swift environmental energy extraction capabilities are likely to be based in morphology and an underexplored ability to sense, predict and exploit beneficial small-scale aerial conditions. Morphologically, swifts have a lower wing loading $\left(26.24 \mathrm{~N} \mathrm{~m}^{-2}\right.$; Henningsson and Hedenström, 2011) than larger thermal soarers such as magnificent frigatebirds $\left(34.76 \mathrm{~N} \mathrm{~m}^{-2}\right.$; Trefry and Diamond, 2017) and exhibit a glide polar with a lower maximum distance speed and slower minimum sink rate, allowing exploitation of smaller and weaker thermals. Prior results predicting thermal soaring radius as a function of wing loading in larger birds (Pennycuick, 1983) indicate that a bird with the swift wing loading should be able to circle in a thermal with a radius of approximately $7 \mathrm{~m}$. For comparison, we identified a swift circling in a thermal with an $8 \mathrm{~m}$ radius at an average airspeed of $6.3 \mathrm{~m} \mathrm{~s}^{-1}$, indicating that common swift performance is consistent with results from larger birds. Interestingly, analysis of swift wake topologies during wind tunnel flight (Henningsson et al., 2014) shows that swift wings are tuned for efficiency in flapping flight over gliding. This is not necessarily inconsistent with our result that gliding and environmental energy extraction dominate foraging behaviour; for a bird that remains in the air nearly year-round, dealing with occasional cases where flapping is required may be more important than further optimization of gliding performance. Thermal use is also known in swifts from their nightly ascents to roosting altitude during the non-breeding season (Hedenström et al., 2016), but the extent to which thermal soaring and other environmental energy extraction are integrated into foraging activities near the nest came as a surprise to us. It is worth noting that thermal soaring while chasing insect prey might be advantageous not only from a biomechanical perspective but also to remain in the vicinity of 'patches' of insects lifted by rising air and thus increase prey encounter probability. Indeed, we recorded several examples of thermal soaring immediately followed by a steep dive towards the nest, suggesting that the energy gain during the ascension was not

Table 5. Free-flight versus wind tunnel glide performance measurements

\begin{tabular}{lllll}
\hline Source & $\begin{array}{l}\text { Maximum duration speed } \\
\left(\mathrm{m} \mathrm{s}^{-1}\right)\end{array}$ & $\begin{array}{l}\text { Minimum sink rate } \\
\left(\mathrm{m} \mathrm{s}^{-1}\right)\end{array}$ & $\begin{array}{l}\text { Maximum range speed } \\
\left(\mathrm{m} \mathrm{s}^{-1}\right)\end{array}$ & $\begin{array}{l}\text { Maximum lift to drag } \\
\text { ratio }\end{array}$ \\
\hline This study & 6.9 & 0.75 & 9.0 & 10.5 \\
Henningsson and Hedenström (2011) & 8.1 & 0.7 & 9.5 & 12.5 \\
Lentink et al. (2007) & 7.6 & 0.8 & 8.3 & 10.5 \\
\hline
\end{tabular}


the birds' primary motivation for thermal soaring (de Margerie et al., 2018).

\section{Limitations and future work}

Our results are unavoidably tied to the environmental and biological context in which they were collected, and understanding the generality of some of the findings here such as the substantial use of environmental energy to power flight will require many more detailed quantitative field flight performance datasets. Another limitation is possible pseudo-replication when recording untagged birds. With an estimation of about 300 birds nesting in the study area, pseudoreplication probably occurred, but simulations show it should be limited to a few tracks in our sample ( 8 recordings out of 73 on average). We hope to see new data collected with a mix of videographic and data-logger recordings in the coming years. We also believe our results should spur some investigation into how swifts or other small birds sense and respond to environmental energy in the form of gusts, thermals or other air movements.

\section{Acknowledgements}

We thank Fouad Nassur and Stéphane Louazon for technical support in the field, Jean Nabucet and Solène Croci for providing a 3D map of the study site for calibration, Corinne Baczkowski (AST35) for providing access to property during swift filming, and Jim Usherwood and Doug Warrick for commenting on earlier versions of the manuscript.

\section{Competing interests}

The authors declare no competing or financial interests.

\section{Author contributions}

Conceptualization: E.d.M.; Methodology: T.L.H., E.d.M.; Software: T.L.H., E.d.M.; Validation: T.L.H., E.d.M.; Formal analysis: T.L.H., E.d.M.; Investigation: C.P., E.d.M.; Data curation: T.L.H., C.P.; Writing - original draft: T.L.H.; Writing - review \& editing: T.L.H., C.P., E.d.M.; Visualization: T.L.H., E.d.M.; Supervision: E.d.M.; Project administration: E.d.M.; Funding acquisition: T.L.H., E.d.M.

\section{Funding}

This work was funded by National Science Foundation IOS-1253276 to T.L.H. and base funding from Centre National de la Recherche Scientifique and Université de Rennes to E.D.M.

\section{Data availability}

The flight trajectory and environmental data used as a basis for this analysis are publicly available from the Dryad digital repository (Hedrick et al., 2018): https://doi. org/10.5061/dryad.89b2c4s

\section{Supplementary information}

Supplementary information available online at

http://jeb.biologists.org/lookup/doi/10.1242/jeb.186270.supplemental

\section{References}

Azuma, A. (1992). The Biokinetics of Flying and Swimming. New York: Springer. Clark, C. J. (2009). Courtship dives of Anna's hummingbird offer insights into flight performance limits. Proc. R. Soc. B Biol. Sci. 276, 3047-3052. de Margerie, E., Simonneau, M., Caudal, J.-P., Houdelier, C. and Lumineau, S. (2015). 3D tracking of animals in the field using rotational stereo videography. J. Exp. Biol. 218, 2496-2504.

de Margerie, E., Pichot, C. and Benhamou, S. (2018). Volume-concentrated searching by an aerial insectivore, the common swift, Apus apus. Anim. Behav. 136, 159-172.

Gory, G. (2008). Diet of the common swift (Apus apus) in the Mediterranean region. Revue d'Ecologie (Terre et Vie) 63, 251-260.

Geerts, B. and Miao, Q. (2005). Airborne radar observations of the flight behavior of small insects in the atmospheric convective boundary layer. Environ. Entomol. 34, 361-377.

Hedenström, A. and Rosén, M. (2001). Predator versus prey: on aerial hunting and escape strategies in birds. Behav. Ecol. 12, 150-156.

Hedenström, A., Alerstam, T., Green, M. and Gudmundsson, G. A. (2002). Adaptive variation of airspeed in relation to wind, altitude and climb rate by migrating birds in the Arctic. Behav. Ecol. Sociobiol. 52, 308-317.

Hedenström, A., Norevik, G., Warfvinge, K., Andersson, A., Bäckman, J. and Åkesson, S. (2016). Annual 10-month aerial life phase in the common swift Apus apus. Curr. Biol. 26, 3066-3070.

Hedrick, T., Pichot, C. and de Margerie, E. (2018). Data from: Gliding for a free lunch: biomechanics of foraging flight in common swifts (Apus apus). Dryad Digital Repository. https://doi.org/10.5061/dryad.89b2c4s

Henningsson, P. and Hedenström, A. (2011). Aerodynamics of gliding flight in common swifts. J. Exp. Biol. 214, 382-393.

Henningsson, P., Johansson, L. C. and Hedenström, A. (2010). How swift are swifts Apus apus? J. Avian Biol. 41, 94-98.

Henningsson, P., Hedenström, A. and Bomphrey, R. J. (2014). Efficiency of lift production in flapping and gliding flight of swifts. PLoS ONE 9, e90170.

Henningsson, P., Muijres, F. T. and Hedenström, A. (2011a). Time-resolved vortex wake of a common swift flying over a range of flight speeds. J. R. Soc. Interface 8, 807-816.

Henningsson, P., Spedding, G. R. and Hedenström, A. (2011b). Vortex wake and flight kinematics of a swift in cruising flight in a wind tunnel. J. Exp. Biol. 214 697-697.

Kogure, Y., Sato, K., Watanuki, Y., Wanless, S. and Daunt, F. (2016). European shags optimize their flight behavior according to wind conditions. J. Exp. Biol. 219 311-318.

Lack, D. and Owen, D. F. (1955). The food of the swift. J. Anim. Ecol. 24, 120-136. Lentink, D., Müller, U. K., Stamhuis, E. J., de Kat, R., van Gestel, W., Veldhuis, L. L. M., Henningsson, P., Hedenström, A., Videler, J. J. and van Leeuwen, J. L. (2007). How swifts control their glide performance with morphing wings. Nature 446, 1082

Pennycuick, C. J. (1978). Fifteen testable predictions about bird flight. Oikos $\mathbf{3 0}$ 165-176.

Pennycuick, C. J. (1983). Thermal soaring compared in three dissimilar tropical bird species, Fregata magnificens, Pelecanus occidentalis, and Coragyps atratus. J. Exp. Biol. 102, 307-325

Shamoun-Baranes, J., van Loon, E., Liechti, F. and Bouten, W. (2007). Analyzing the effect of wind on flight: pitfalls and solutions. J. Exp. Biol. 210 82-90

Shelton, R. M., Jackson, B. E. and Hedrick, T. L. (2014). The mechanics and behavior of cliff swallows during tandem flights. J. Exp. Biol. 217, 2717-2725.

Trefry, S. A. and Diamond, A. W. (2017). Exploring hypotheses for sexual size dimorphism in frigatebirds. Evol. Ecol. Res. 18, 225-252.

Wainwright, C. E., Stepanian, P. M., Reynolds, D. R. and Reynolds, A. M. (2017). The movement of small insects in the convective boundary layer: linking patterns to processes. Sci. Rep. 7, 5438.

Wakeling, J. M. and Hodgson, J. (1992). Short communication: optimisation of the flight speed of the little, common and sandwich tern. J. Exp. Biol. 169, 261-266.

Warrick, D. R., Hedrick, T. L., Biewener, A. A., Crandell, K. E. and Tobalske B. W. (2016). Foraging at the edge of the world: low-altitude, high-speed manoeuvering in barn swallows. Phil. Trans. R. Soc. B Biol. Sci. 371, 20150391. 


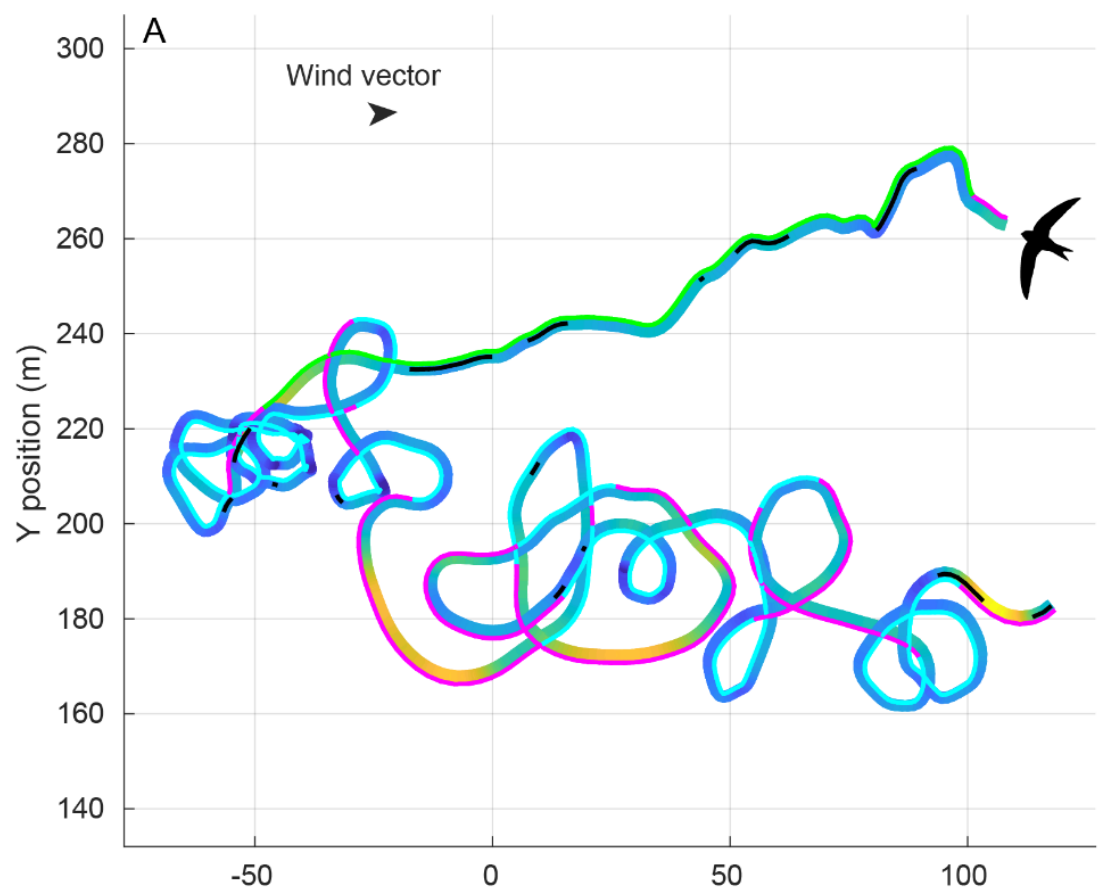

Figure S1: Here we show a sample common swift flight track from the dataset which includes a long section where the swift appears to, with occasional interruptions, circle and rise in a thermal. Panel (A) provides an overhead and $(B)$ a side view of ground reference frame position. The swift silhouette (not to scale) marks the start in each panel. Flight speed is shown by colour in the wider ribbon, with a black line overlaid when the bird was flapping. Note that the flight speed colour range is specific to this figure and not identical to Fig. 2.
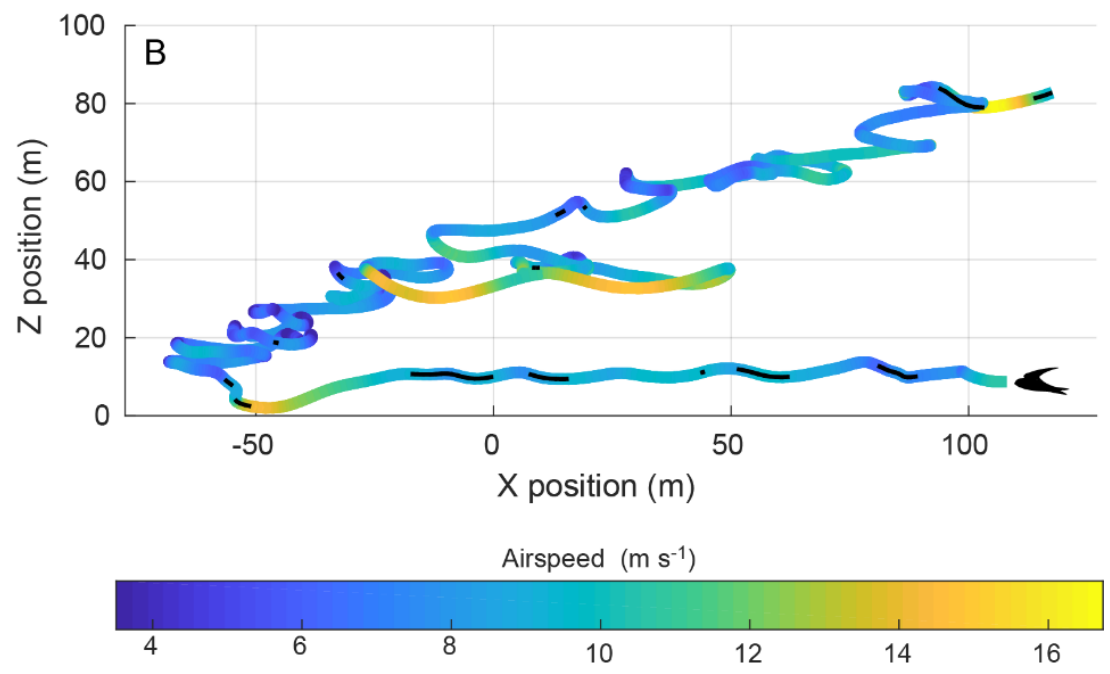

Flight behavior

\begin{tabular}{|c|c|c|}
\multicolumn{2}{c}{ Flight behavior } & Flapping flight \\
\hline Straight & Meandering Circling &
\end{tabular}




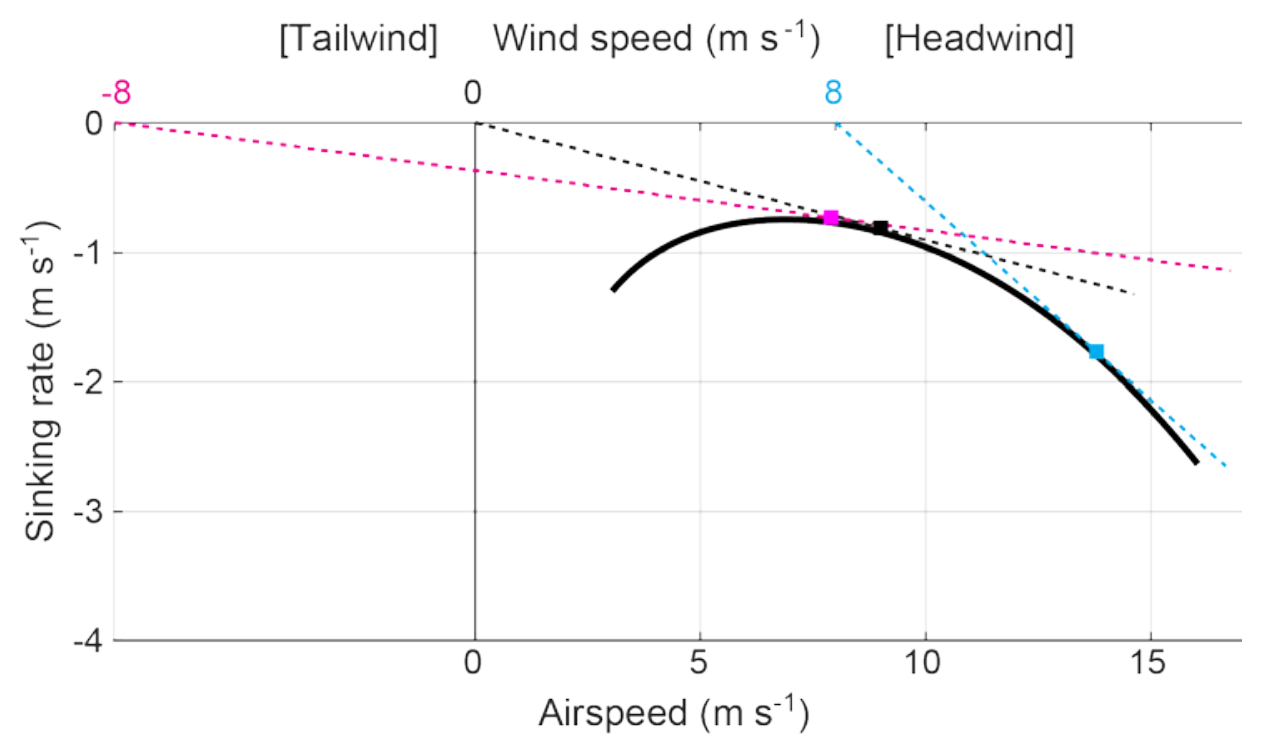

Figure S2: Here we use the glide polar (thick black line) from Figure 5 to show the effect of an $8 \mathrm{~m} \mathrm{~s}^{-1}$ headwind or tailwind on the predicted maximum range speed, shown as a square on the glide polar for each case. For the tailwind, this analysis predicts an optimal airspeed of $7.9 \mathrm{~m} \mathrm{~s}^{-1}$ for the tailwind and $13.8 \mathrm{~m} \mathrm{~s}^{-1}$ for the headwind, resulting in respective ground speeds of $15.9 \mathrm{~m} \mathrm{~s}^{-1}$ and $5.8 \mathrm{~m} \mathrm{~s}^{-1}$. Based on the analysis in Fig. 3, the actual swift responses under these conditions were to fly at airspeeds of $7.9 \mathrm{~m}$ $\mathrm{s}^{-1}$ and $13.1 \mathrm{~m} \mathrm{~s}^{-1}$. 


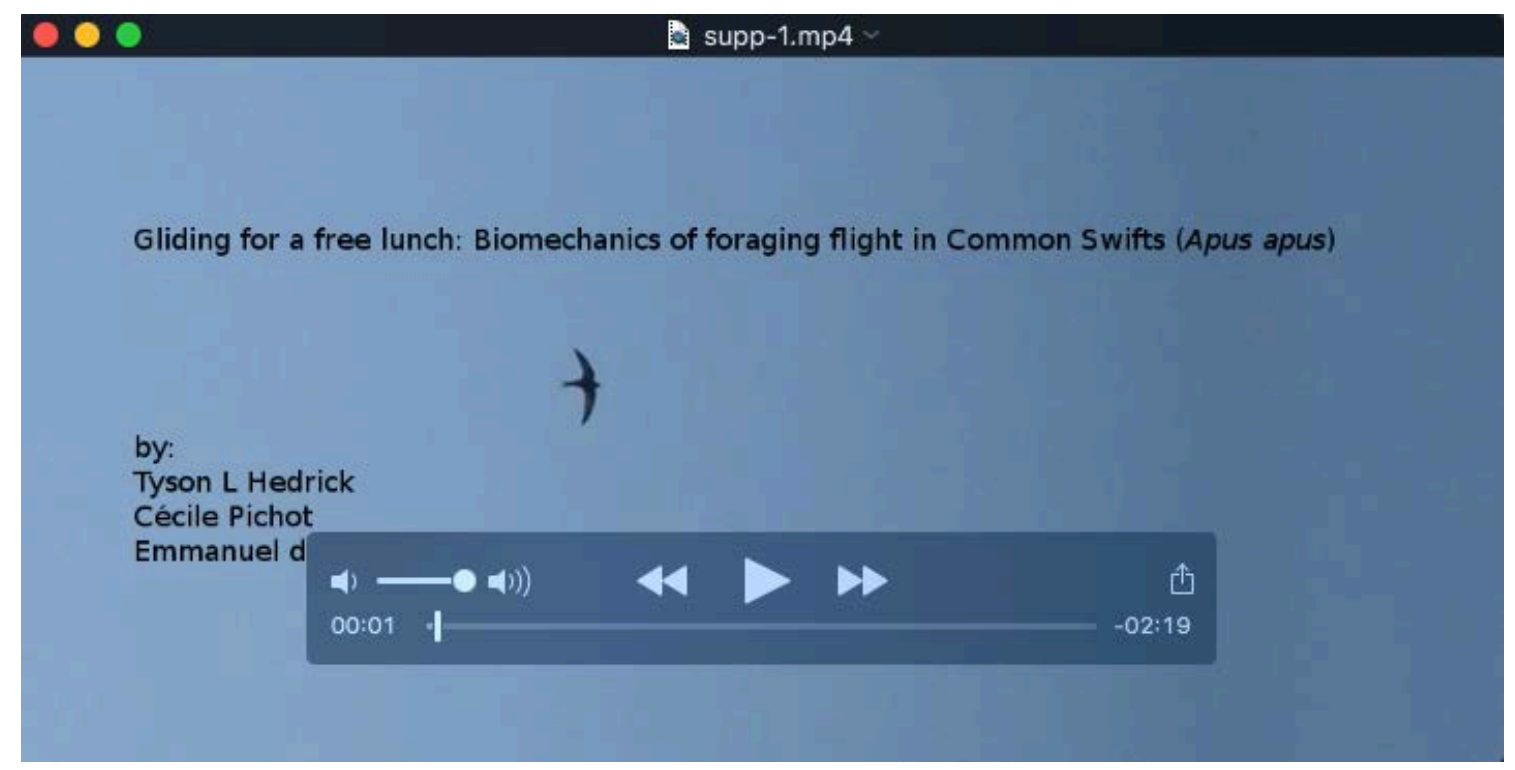

Movie 1: This supplementary video shows the source video image of the swift, cropped from the original recording to show detail and overlaid with many of the kinematic and behavioural quantities computed during our analysis. The right side panels show the overhead and lateral view, colour-coded to indicate flight speed and flapping activity. Video playback is at half of live speed. 